\begin{tabular}{|lcc|}
\hline \multicolumn{3}{|c|}{ TOTOBUANG } \\
\hline Volume 6 & Nomor 2, Desember 2018 & Halaman 283-296 \\
\hline
\end{tabular}

\title{
NILAI MORAL DALAM SYAIR KABANTI GANDA DI KELURAHAN WABOROBO KECAMATAN BETOAMBARI KOTA BAUBAU (Moral Values In Syair Kabanti Ganda Waborobo Village, Betoambari District, Baubau City)
}

\author{
Nadir LA Djamudia,", Mahfuddin ${ }^{\mathrm{b}, *}$, \& Asrul Nazar,", \\ a , c Universitas Muhammadiyah Buton \\ Jl. Betoambari, Kota Baubau, Provinsi Sulawesi Tenggara, Indonesia \\ ${ }^{b}$ Universitas Muhammadiyah Bone \\ Kabupaten Bone, Sulawesi Selatan \\ Pos-el: nadirladjamudi@gmail.com,
}

(Diterima: 5 November 2018; Direvisi: 6 Desember 2018; Disetujui: 19 Desember 2018)

\begin{abstract}
This study aims to describe moral values in Syair Kabanti Ganda Waborobo Village, Betoambari District, Baubau City. This study used descriptive qualitative method. Research data are in the form of speech which were contained in words, sentences that contain moral values in Syair Kabhanti Ganda. Data collection uses recording and note-taking techniques. The moral values of the three syair Kabanti Ganda; (1) Moral Value in Kabanti Ngkitaana: (a) Principle of Good Attitude; human awareness of the existence of humanity. $(b)$ the principle of harmony; call for harmony among human being because we are from one origin. (2) Moral Value of Kabanti Yoai: (a) Good Attitude Principle in the form of tabe words when passing in front of a person or many people or during a meeting. (b) The principle of harmony in the form of mutual advice and respect for one another. (c) Respectful Principles in the form of respect and submission to mother. (3) The Moral Value of Yoisa Kabanti: (a) The principle of harmony in communication that is very tolerant and moves between brothers and sisters. (b) The principle of Respect in the form of respects and obeys his brother. Therefore,the brother must love his sister. (c) The Godhead Principle in the form of belief in the provisions of the Lord.
\end{abstract}

Keywords: Moral Value, Syair Kabanti Ganda

\section{Abstrak}

Penelitian bertujuan untuk mendeskripsikan nilai moral dalam Syair Kabanti Ganda Kelurahan Waborobo, Kecamatan Betoambari, Kota Baubau. Penelitian lapangan ini menggunakan metode deskriptif kualitatif. Data penelitian berupa tuturan dalam bentuk kata, kalimat yang mengandung nilai moral dalam syair Kabhanti Ganda. Pengumpulan data menggunakan teknik rekam dan teknik catat. Nilai moral 3 syair Kabanti Ganda yang berjudul; (1) Nilai Moral dalam Kabanti Ngkitaana: (a) Prinsip Sikap Baik; pentingnya kesadaran manusia akan eksistensi kemanuasiaan. (b) Prinsip Kerukunan; seruan untuk rukun bagi umat manusia karena kita satu asal. (2) Nilai Moral Kabanti Yoai: (a) Prinsip Sikap Baik dalam bentuk kata tabe disaat melintas di depan seseorang atau banyak orang atau disaat meninggalkan pertemuan. (b) Prinsip Kerukunan dalam bentuk sikap saling menasihati dan saling memperhatikan satu sama lain. (c) Prinsip Hormat dalam bentuk hormat dan patuh kepada ibu. (3) Nilai Moral Kabanti Yoisa: (a) Prinsip Kerukunan dalam komunikasi yang sangat toleran dan saling mengindahkan di antara adik dan kakak. (b) Prinsip Hormat dalam wujud sang adik menghormati dan patuh kepada kakaknya. Demikian pula, sang kakak harus menyayangi adiknya. (c) Prinsip Ketuhanan dalam wujud keyakinan atas ketetapan Tuham.

Kata-kata Kunci: Nilai Moral, Syair Kabanti Ganda

\section{PENDAHULUAN}

Keanekaragaman budaya di Indonesia melahirkan keanekaragaman sastra yang menjadi miniatur ciri kedarahan masingmasing daerah atau etnis di Indonesia. Sastra daerah merupakan bagian dari kebudayaan yang tumbuh dan berkembang di tengahtengah masyarakat pendukungnya. Kehidupan sastra daerah itu dapat dikatakan masih berkisar pada sastra lisan yang sebagian besar tersimpan dalam ingatan 
orang tua atau pencerita yang jumlahnya semakin berkurang dimakan usia.

Sastra daerah sebagai kebudaya-an daerah yang mempunyai peran yang sangat penting dalam upaya pengem-bangan kebudayaan nasional. Untuk itu penggalian kebudayaan daerah memerlukan data dan informasi yang lengkap sehingga keanekaragaman kebudayaan tersebut dapat mewujud-kan kesatuan bangsa melalui sastra daerah yang dimilikinya. Salah satu informasi yang sangat penting yaitu adanya sastra daerah yang masih berbentuk lisan dan masih terdapat di tengah- tengah masyarakat, serta diwarisi dan disebarkan secara turun temurun dari generasi kegenerasi berikutnya secara lisan.

Fungsi dan kedudukan sastra lisan itu sangat penting untuk mendukung usaha kegiatan pengem-bangan sastra tradisional yang menjadi aspirasi dan kreasi yang akan memperkaya dan mempermantap wawasan budaya bangsa Indonesia. Oleh karena itu sastra daerah merupakan gambaran dari alam budaya bangsa Indonesia.

Sastra lisan adalah suatu karya sastra daerah yang banyak ditemukan di Indonesia. Salah satu dari sekian banyak yang mewarisi sastra lisan daerah adalah masyarakat Waborobo. Sastra lisan masyarakat Waborobo yang dimiliki masyarakat Waborobo sangat beraneka ragam jenisnya. Jenis sastra lisan yang dimiliki masyarakat Waborobo adalah berbagai jenis cerita rakyat berupa mite, dongeng, legenda maupun fabel, serta nyanyian rakyat. Sastra daerah tersebut merupakan warisan yang sangat tinggi nilainya dan masih dihargai dan dipelihara oleh masyarakat Waborobo.

Syair Kabanti Ganda merupa-kan salah satu sastra lisan masyarakat Waborobo yang biasa dilantunkan pada prosesi budaya yang disebut Moose'a (acara pingitan) sebagai warisan sejak zaman dahulu hingga saat ini. Proses Moose'a (acara pingitan) dilaksanakan untuk puluhan anak gadis di kampmpung tersebut yang baru saja melewati masa menstruasi pertama.
Pada prosesi adat Moose'a (acara pingitan) selama tujuh malam atau delanpan malam inilah para orang tua melantunkan nyanyian yang kemudian disebut dengan Syair Kabanti Ganda. Syair Kabanti Ganda ini masih dipertahankan oleh masyarakat Waborobo sekaligus sebagai ciri khas budaya masyarakat pemiliknya. Masyarakat Kelurahan Waborobo Kecamatan Betoambari Kota Baubau masih merasakan betapa penting dan urgensinya nilai-nilai kehidupan sosial keagamaan yang terkandung dalam prosesi dan nyanyian tersebut. Dengan demikian, peneliti termotivasi untuk mengkaji lebih dalam tentang nilai-nilia moral yang terkandung di dalam Syair Kabanti Ganda tersebut.

Fokus penelitian ini adalah bagaimanakah nilai moral dalam Syair Kabanti Ganda di Kelurahan Waborobo Kecamatan Betoambari Kota Baubau? Tujuan penelitian ini adalah untuk mendeskripsikan nilai moral dalam Syair Kabanti Ganda di Kelurahan Waborobo Kecamatan Betoambari Kota Baubau. Manfaat penelitian ini adalah: (1) bahan studi perbandingan dari penelitian selanjutnya yang dianggap relevan. (2) informasi tentang kandungan nilai dalam Syair Kabanti Ganda di Kelurahan Waborobo Kecamatan Betoambari Kota Baubau. (3) Masukan bagi pihak Departemen Pendidikan Nasional dalam rangka mempertimbangkan perlunya muatan lokal muatan lokal.

\section{LANDASAN TEORI}

\section{A. Pengertian Kebudayaan}

Kata "kebudayaan berasal dari (bahasa Sanskerta) yaitu "buddayah" yang merupakan bentuk jamak dari kata "budhi" yang berarti budi atau akal. Kebudayaan diartikan sebagai "hal-hal yang bersangkutan dengan budi atau akal". Pengertian Kebudayaan secara umum adalah hasil cipta, rasa dan karsa manusia dalam memenuhi kebutuhan 
hidupnya yang kompleks yang mencakup pengetahuan, keyakinan, seni, susila, hukum adat dan setiap kecakapan, dan kebiasaan (Soemardjan, dkk., 2012: 112). Sedangkan menurut Baker (2011: 24) yang mengatakan bahwa pengertian kebudayaan adalah keseluruhan manusia dari kelakuan dan hasil yang harus didapatkannya dengan belajar dan semua itu tersusun dalam kehidupan masyarakat.

Dijelaskan oleh Tylor (2014: 233) bahwa pengertian kebudayaan dalam bahasa inggris disebut culture. merupakan suatu istilah yang relatif baru karena istilah culture sendiri dalam bahasa inggris baru muncul pada pertengahan abad ke-19. Sebelumnya pada tahun 1843 para ahli antropo-logi memberi arti kebudayaan sebagai cara mengolah tanah, usaha bercocok tanam, sebagaima-na tercermin dalam istilah agricul-ture dan holticulture. Hal ini bisa kita mengerti karena istilah culture berasal dari bahasa Latin colere yang berarti pemeliharaan, pengolahan tanah pertanian. Pada arti kiasan kata itu juga berarti "pembentukan dan pemurnian jiwa". Kebudayaan adalah kom-pleks yang mencakup pengetahuan, kepercayaan, kesenian, moral, hukum, adat istiadat, dan lain kemampuankemampuan serta kebiasaan-kebiasaan yang didapat-kan oleh manusia sebagai anggota masyarakat.

Kebudayaan adalah pen-ciptaan, penebitan, dan pengolahan nilai-nilai insani, terlingkup di dalamnya usaha memanusiakan bahan alam serta hasilnya (Baker, 2011: 22). Menurut Zulvita, dkk (2013: 32) mengemukakan bahwa budaya merupakan pengetahuan yang dapat dikomunikasi, sifat-sifat perilaku yang dipelajari yang juga ada anggotaanggota suatu kelompok sosial dan berwujud dalam lembaga-lembaga dan aspek -aspek mereka.

Pengetahuan budaya diba-tasi sebagai pengetahuan yang mencakup keahlian (disiplin) seni dan filsafat. Keahlian ini pun dibagi-bagi berbagai bidang keah-lian lain seperti seni sastra, seni tari, seni rupa dan lain-lain (Mustopo, 2012: 16).

\section{B. Pengertian Sastra Lisan}

Sastra lisan adalah karya sastra yang diciptakan dan disampaikan secara lisan dengan mulut, baik dalam pertunjukan seni maupun di luarnya. Hutomo (dalam Depdikbud, 2010: 1) mengatakan bahwa sastra lisan adalah karya seni yang menggunakan bahasa lisan, yang diungkapkan dari mulut ke mulut, yang berisikan makna kehidupan dan nilai-nilai luhur dan pengajaran.

Sastra lisan yaitu karya yang dikarang menurut standar bahasa kesusastraan dan diteruskan dari orang ke orang dalam bentuk tidak berubah dengan lisan bukan tulisan, (Kridalaksana, 2012: 172).

Menurut Gafar (2011: 3) sastra lisan adalah jenis karya yang diturunkan dari mulut ke mulut, tersebar secara lisan anonym dan menggambarkan kehidupan pada masa lampau.

\section{Ciri-ciri Sastra Lisan}

Menurut Hutomo (dalam Depdikbud, 2009: 13) ciri-ciri sastra lisan sebagai berikut:

1. Anonym, yaitu karya sastra itu tidak diketahui pengarangnya.

2. Statis yaitu baik isi maupun bentuk contohnya sangat lambat perubahannya.

3. Religiusitas yaitu karya-karya itu berhubungan dengan agama dan kepercayaan yang dianut.

4. Klise imajinatif yaitu baik isi maupun bentuknya selalu meniru bentuk yang sudah ada sebelumnya.

\section{Fungsi Sastra Lisan}

Menurut Setia (2014: 17) fungsi sastra lisan adalah sebagai berikut: 
1. Sebagai sistem proyeksi yaitu sebagai pencerminan angan-angan suatu kolektif.

2. Sebagai alat pengesahan pranatapranata dan lembaga-lembaga untuk kemajuan dirinya.

3. Sebagai alat pendidikan anak.

4. Sebagai alat pemaksa dan pengawas agar norma-norma masyarakat selalu dipatuhi angota kolektif.

Menurut Apitukey (2010: 12)

fumgsi sastra lisan adalaha:

1. Fungsi mendidik:

a. Membina tingkah laku yang baru, agar tercapai keserasi-an hidup bersama

b. Membina kemampuan dan perasaan.

c. Mendidik moral yang tinggi seperti, jujur, belas kasihan dan suka menolong.

2. Fungsi menyimpan budaya dengan mendengar sastra lisan, generasi muda mengetahui bagaimana setiap hidup yang luhur dari nenek moyang.

3. Fungsi motivasi, agar generasi muda dapat mengambil manfaat dari sastra lisan tersebut.

4. Fungsi rekreasi

Jika diamati dari fungsi sastra lisan di atas maka nyanyian tradisional dalam Syair Kabanti Ganda sebagai salah satu bentuk sastra lisan masyarakat Ciacia dapat pula menunjukan fungsi sebagaimana yang diuraikan di atas yaitu sebagai alat penghibur, sarana pendidikan, dan sarana rekreasi.

Menurut Zainal (2016: 34, sastra lisan termasuk folklor lisan dan sebagian lisan, mempunyai empat fungsi , yaitu: (1) Sebagai bentuk hiburan, (2) Sebagai alat pengesahan, (3) Sebagai alat pendidikan anak, (4) Sebagai alat pemaksa agar norma-norma masyarakat dipatuhi.

Sastra lisan sebagai sistem proyeksi terkait dengan keinginan keinginan bawah sadar manusia atau hanya dalam angan-angan. Misalnya, cerita Bawang
Putih dan Bawang Merah merupakan proyeksi atau pencerminan adanya keinginan gadis miskin yang cantik untuk diperistri orang kaya, bangsawan atau pangeran. Fungsi sastra lisan untuk memberikan suatu jalan yang diberikan oleh masyarakat agar dia dapat lebih superior dibanding orang lain.

Sastra lisan juga berfungsi untuk memberikan seseorang suatu jalan yang diberikan oleh masyarakat agar dia dapat mencela orag lain. Sastra lisan berfungsi sebagai alat untuk memprotes ketidakadilan dalam masyarakat. Sastra lisan juga berfungsi sebagai hiburan. Fungsi-fungsi sastra lisan tersebut saling berkaitan. Sebuah cerita lisan yang ditemukan oleh seorang peneliti dapat dikaitkan demgan berbagai fungsi yang ada.

\section{E. Bentuk-bentuk Sastra Lisan}

Secara umum ragam sastra atau genre sastra berdasarkan situasi bahasanya, (diilhami oleh pendapat Plato) menurut Luxemburg, dkk. (2010: 52) terdiri atas tiga: (1) Teks monolog, yaitu teks yang dibawakan oleh satu pencerita, misalnya; pidato, khotbah, uraian, dan sebagainya. (2) Teks dialog, yaitu teks yang sekurang-kurangnya dibawakan oleh dua pembicara secara bergantian, misalnya berupa, drama, tragedi komedi, dan drama keluarga. (3) Teks berlapis, yaitu teks yang memuat pembicara utama atau pencerita primer yang dapat menampilkan pembicara lain, yaitu tokoh. Dalam hal ini teks tokoh merupakan lapisan yang bertumpuh pada teks pencerita utama. Misalnya, roman, epos, dan cerpen.

Akan tetapi, secara khususn, Shipley (dalam Gaffar, dkk., 2011: 54) menjelaskan bahwa sastra lisan adalah jenis atau kelas karya sastra tertentu, yang dituturkan dari mulut ke mulut, tersebar secara lisan, anonim dan menggambarkan 
kehidupan masyarakat pada masa lampau. Jenis sastra lisan meliputi:

1. Bahasa rakyat: logat, sindiran, bahasa rahasia, dan mantra;

2. Ungkapan tradisional: pribahasa, pepatah, dan seloka;

3. Pertanyaan tradisional: teka-teki, wangsalan;

4. Puisi rakyat: pantun, syair, dan gurindam;

5. Cerita prosa rakyat: mite, legenda, dongeng, fable, cerita jenaka, ;

6. Nyanyian rakyat.

Suripan (dalam Sarjono, 2013: 4) menjelaskan bahwa sastra lisan atau kesusastraan lisan adalah kesusastraan yang mencakup hasil ekspresi warga suatu kebudayaan masyarakat tertentu yang turun-temurun dan disebarluaskan secara lisan dari mulut ke mulut.

Menurut Danandjaja (2011: 41) bentuk-bentuk sastra lisan adalah:

1. Bahasa rakyat adalah suatu bentuk bahasa yang digunakan dalam kehidupan sehari-hari, baik suasana pergaulan maupun dalam situasi khusus, misalnya dalam upacaraupacara keaga-maan.

2. Ungkapan tradisional adalah bahasa yang digunakan dalam kehidupan sehari-hari baik suasana pergaulan maupun dalam situasi khusus, misalnya dalam upacara-upacara keaga-maan.

3. Pertanyaan tradisional adalah bahasa yang berisi pertanyaan-pertanyaan yang berupa teka-teki, dan bentuk bahasa ini biasanya digunakan seseorang mengasah otak.

4. Cerita rakyat adalah kiasan antonim yang tidak terikat pada orang dan waktu yang beredar secara lisan di tengah-tengah masyarakat.

5. Puisi rakyat (puisi lama) yaitu bentuk sastra lisan yang biasanya selalu terikat dengan aturan-aturan atau syarat-syarat tertentu yakni berupa jumlah baris, jumlah bait, irama maupun bentuk persajakan.

6. Nyanyian rakyat yaitu salah satu bentuk sastra lisan yang terdiri dari kata-kata dan lagu yang beredar secara lisan di antara kolektif tertentu, yang berbentuk tradisional.

\section{F. Pengertian Nyanyian Rakyat}

Dalam Kamus Istilah Sastra (Zainal, 2016: 72) mengemukakan bahwa lagu rakyat adalah nyanyian yang merupakan tradisi lisan dari masyarakat suatu daerah yang mencerminkan gaya hidupnya. Selanjtnya, Bruvand (dalam Danandjaja, 2011: 141) mengatakan bahwa nyanyian rakyat adalah nyanyian yang terdiri dari kata-kata dan lagu yang beredar secara lisan dalam suatu masyarakat tertentu yang berbentuk tradisional serta mempunyai banyak varian.

Sejalan dengan pendapat para ahli di atas, maka peneliti dapat menyimpulkan bahwa Syair Kabanti Ganda adalah kata-kata nyanyian lisan dari mulut ke mulut yang secara turuntemurun dari nenek moyang, anonim, dan bersifat tradisi menurut adat kebiasaan yang dijalankan oleh Masyarakat Kelurahan Waborobo Kecamatan Betoambari Kota Baubau.

\section{G. Fungsi Nyanyian Rakyat}

Menurut Setia (2014: 20), fungsi nyayian rakyat sebagai berikut:

1. Fungsi kreatif, yaitu merenggut dari kebosanan hidup sehari-hari walaupun untuk sementara waktu atau untuk menghibur diri dari kesukaran hidup, sehingga dapat pula menjadi semacam pelipur lara atau untuk melepaskan diri segala ketegangan perasaan sehingga dapat memperoleh kedamaian jiwa.

2. Sebagai pembangkit semangat jiwa.

3. Untuk memelihara sejarah setempat.

4. Sebagai proses sosial. 


\section{H. Hakikat Nilia Moral}

Secara etimologis, kata moral berasal dari kata mos dalam bahasa Latin, bentuk jamaknya mores, yang artinya adalah tata-cara atau adat-istiadat. Dalam Kamus Besar Bahasa Indonesia (2014: 592), moral diartikan sebagai akhlak, budi pekerti, atau susila. Secara terminologis, terdapat berbagai rumusan pengertian moral, yang dari segi substantif materiilnya tidak ada perbedaan, akan tetapi bentuk formalnya berbeda. (Wahid, 2015: 17). Moral merupakan kondisi pikiran perasaan, ucapan, dan perilaku manusia yang terkait dengan nilai-nilai baik buruknya, (Suseno, 2011: 645). Moral juga dapat diartikan sebagai sikap, perilaku, tinadakan, kelakuan, yang dilakukan seseorang pada saat mencoba melakukan sesuatu berdasarkan pengalaman, tafsiran, suara hati, serta nasihat dan lain-lain. Suseno (2011: 18) menyatakan bahwa sikap moral sebenarnya adalah moralitas. Moral atau moralitas mengacu pada baik buruknya manusia sebagai manusia, sedangkan bidang moral adalah kehidupan masyarakat dilihat dari segi kebaikannya. Norma-norma moral adalah tolak ukur yang dipakai masyarakat utuk mengukur kebaikan seseorang.

Nilai berarti sifat atau kualitas yang melekat pada suatu objek, bukan objek itu sendiri. Sesuatu dikatakan bernilai apabila sesuatu itu berharga, berguna, benar, indah, baik, dan lain sebagainya. (Darmadi, 2010: 67) . Herimanto dan Winarto (2013: 129) berpendapat bahwa kata moral berarti akhlak atau kesusilaan yang mengandung makna tata tertib batun atau tata tertib hati nurani yang menjadi pembimbing tingkah laku batin dalam hidup. Jadi nilai moral adalah segala aspek yang menyangkut baik buruknyasuatu perbuatan atau tingkah laku yang berasal dari hati nurani dan harus direalisasikan.
Dalam hal ini mengenai sikap, kewajiban, akhlak, budi pekerti dan susiala.

Menurut Salam (2013: 168) akhlak terpuji dapat terwujud apabila kita memiliki sifat-sifat terpuji pula, yaitu sabar, benar, amanah, adil, kasih sayang, hemat, berani, kuat, malu, memelihara kesucin diri, dan menepati janji. Sifatsifat terpuji tersebut merupakan nilai-nilai moral yang harus diwujudkan apabila seseorang ingin memiliki moral yang baik.

Nilai moral yang dideskripsi-kan terdiri atas nilai moral positif dan negatif. Adapun tolak ukur untuk menentukan nilai moral positif dan negatif didasarkan pada landasan kaidah dasar moral. Landasan kaidah dasar moral menurut Suseno (2011: 129) adalah (1) prinsip sikap baik, (2) prinsip keadilan, dan (3) prinsip menghar-gai diri sendiri. Selanjutnya Suseno (2011:39) mengungkapkan dua kaidah dasar moral yaitu, (1) prinsip kerukunan, dan (2) prinsip hormat. Adapun Zubair (2016: 78) mengungkapkan tiga kaidah dasar moral, yaitu (1) kaidah sikap baik, (2) kaidah keadilan, dan (3) kaidah ketuhanan.

\section{METODE PENELITIAN}

Penelitian ini menggunakan metode penelitian deskriptif kualitatif. Jenis penelitian ini adalah penelitian lapangan. Data penelitian ini adalah tuturan lisan berupa kata-kata atau kalimat yang mengandung nilai moral dalam syair Kabhanti Ganda. Sumber data dalam penelitian ini adalah informan penutur asli atau pelantun asli Syair Kabanti Ganda pada Masyarakat Kelurahan Waborobo Kecamatan Betoambari Kota Baubau.

Pengumpulan data menggunakan teknik rekam dan teknik catat.Teknik rekam digunakan untuk merekam syair Kabanti Ganda yang dilantunkan secara lisan oleh informan utama yaitu penutur asli atau pelantun asli Syair Kabanti Ganda. Teknik catat digunakan dengan cara mencatat data 
yang dianggap penting di luar data rekaman untuk mendapatkan data yang komprehensif.

Data dalam penelitian ini dianalisis secara deskriptif kualitatif yang mengacu pada pendapat Ratna (2015: 53) bahwa mula-mula data dideskripsikan dalam bentuk kata-kata atau kalimat untuk menemukan unsur-unsurnya yang dilakukan dengan tahapan-tahapan:

1. Transkripsi rekaman data, yaitu memindahkan data ke dalam bentuk tulisan yang sebenarnya.

2. Klasifikasi data, yaitu semua data yang memenuhi syarat dikumpul-kan sesuai dengan karakteristik bentuknya.

3. Penerjemahan data, pada tahap ini semua data yang sudah dikelom-pokkan langsung diterjemahkan ke dalam bahasa Indonesia.

4. Analisis data, tahap ini peneliti berusaha untuk menganalisis semua data yang terkumpul berdasarkan maknanya.

\section{PEMBAHASAN}

Uraian tentang nilai moral dalam teks syair Kabhanti Ganda mengacu pada pendapat Suseno (2011: 129) dan Zubair (2016: 78), bahwa nilai moral terbagi atas; (1) prinsip sikap baik, (2) prinsip keadilan, (3) prinsip menghargai diri sendiri, (4) prinsip kerukunan, (5) prinsip hormat, (5) prinsip ketuhanan. Perpaduan kedua pendapat ini lah yang digunakan peneliti dalam penyajian hasil penelitian dan pembahasan.

\section{Kabanti Ngkitaana}

Kabanti Ngkitaana merupa-kan salah satu jenis Kabanti Ganda dalam acara pingitan pada masyarakat Kelurahaman Waborobo. Kabanti Ngkitaana adalah Kabanti yang dilantunkan Pandeno Ganda (Penabu Gendang) untuk mengingatkan pada manusia bahwa pada mulanya manusia adalah satu yang diciptakan oleh Tuhan dan kemudian menyebar ke seluruh penjuru dunia. Kata ngkitaana berasal dari ngkita dan ana yang artinya "kita ini". Kemudian Kabanti Ngkitaana berarti Kabanti yang menceritakan hakikat kekitaan atau hakikat keberadaan kita sebagai mahluk sosial dan sebagai hamba Allah, lalu mempunyai keturunan yang menyebar hingga keseluruh penjuru dunia.

Untuk lebih jelasnya Kabanti Ngkitaana dapat kita lihat pada kutipan berikut ini.
Ngkaasi ngkitaana
Puuna rapuu-рuи
Kulaseno rumambano
Tano rambamo ku/ese
Puиna sepu'u-pu'u
Puuno wasakalambe
Kuleseno Iaudia
Alindara kuleseno
Notondu ransano Iiwu
Nokopera situmpano
Nolele sambara nggunu
Bhakeno sau mparae
Mantale mie junia
Bhakeno sau lagundi
Labua kalembanguni

Artinya:

Kalembangu bhakeno

Labuansum-suru mbungano

Mbunga sembunga-mbungano

Kita-sekalian manusia

Mulanya dari satu pohon

(kemudian) akhirnya merambat

Biarpun dimana akamya

Pohonya tetap satu

Pohonnya adalah wasakalambe

Akarnya adalah keturunannya

Kutelusuri akamya

Tenggelam di dasar negeri

Tiba (berkembang) di

Penghujung tertentu

Meleleh sembarang gunung

Buahnya kayu mparae

Terceoer manusia di dunia

Buahnya kayu iagundi

Terus di kunjungi

Dikunjungi buahnya

Terus ditelusuri dan ditelusuri bunganya

Adalah berbunga sama

\section{Kabanchlno Yoai}

Kabanti Yoai merupakan salah satu jenis Kabanti Ganda yang mengisahkan kehidupan dan komunikasi yang gaib di dalam kandungan ibu yang sebentar lagi akan melahirkan. Komunikasi gaib yang 
dimaksud adalah komunikasi antara janin bayi dengan kakanya (ari-arinya). Pada akhir Kabanti Yoai juga mengisahkan tentang penderitaan sang ibu disaat menunggu kelahiran bayinya yang belum juga keluar atau lahir.

Untuk lebih jelasnya Kabanti Yoai dapat dilihat pada kutipan berikut di bawah ini.

Tabe lain tabea

Aomangka powandi

Nae tompamo kamborara

Lampangulu notingkulu

Notingkulu rato idhia

Ane sampumo wangu

Tobhiru nungguawe

Anembuli ntugu

Dhotingkulu dharodua

Dhotingkulu tokombowa

Topombuli toponggaamo

Isabharano wamba

Wa inamo pangulumo

Sawali maka iyau

Dopotingalu-ngalumo

Adik, aku duluan lewat

Dipenghujung terang

Yang sakit akan turun

Turun menemui dia

Artinya:

Kalau turun minta izin

Potonglah dengan daun

Kalau puiang tunggulah

Kita turun berdua

Berpegang tangan

Kita turun bersama

Kita pulang berpisahlah

Tapi tinggal kata-kata

Dan sang ibu yang sakit

Padahal saja aku

Hanya desah nafas

\section{Kabantino Yoisa}

Kabanti yoisa merupakan salah satu jenis Kabanti Ganda pada upacara adat pingitan. Kata yoisa secara etimologi berarti "kakak", sedangkan dalam istilah kedokteran yoisa berarti ari-ari bayi. Kabanti yoisa menggambar-kan dialog antara bayi (sebagai adik) dengan ari-ari bayi (sebagai kaka). Dikisahkan dalam Kabanti ini bahwa sang adik sudah kesakitan hendak keluar (lahir) tapi kakanya belum juga mau keluar atau lahir. Ajakan adik dengan berbagai argumen akhirnya dituruti dengan ucapan bahwa saya (kakak) memang sudah begini, nanti lah saya menyusul.

Untuk lebih jelasnya Kabanti Yoai dapat dilihat pada kutipan berikut ini:

Wa aka maimo sampu

Wa andi nopangulumo

Maimo dhia maimo

Koe dhia mbalengo

Ambea lengomo bhela

Ngkapea neantagimo

lyau ngahanea nomo

Madhapo amangka tulu

Atumutumo kabhori

Kabhori minae yopu

Kasukara /ancangia

Kokombe ntagia

Bharanomo mpulawangi

Atuamangi koesu

lyau amokulamo

Kacintampe Iampangulu

Dhamule muIeimo

Kasimbi garanano uwe

Dhamotembe-tembemo

Amoa-moaleimo

Asambi waambie

Ambo kawasakalambe

Kaasi yau wana

Artinya:

Sang kakak marilah turun

Sang adik sudah gelisah (saklt)

Marlah ! marilah!

Jangan tetap enggan (bersama)

Kalau tetap enggan

Kesedihan telah menunggumu

Aku sudah memang begini

Nanti ku susuli

Kututupi ketetapan (tulisan)

Ketetapan dari Tuhan

Kesukaran sebelumnya (tanda

Tanda sebelumnya)

Kutedatuh bertahan

Untunglah melawannya

Kutahan dirimu (kamu)

Daun untuk yang gelisah

(sakit)

(telah) hilang sedikit demi

Sedikit (tak ada panasnya)

Aku bersusah-susah

Gelisah dan gelisah

(kalau) kawasakalambe

Kasihan aku ini

\section{A. Nilai Moral Kabanti Ngkitaana}


Ngkaasi ngkitaana

Puuna rapuu-puu

Kulaseno

rumambano

Tano rambamo

kulese

Puиna sepu'u-pu'u

Puuno wasakalambe

Kuleseno laudia

Alindara kuleseno

Notondu ransano

liwu

Nokopera situmpano

Nolele sambara

nggunu

Bhakeno sau mparae

Mantale mie junia

Bhakeno sau lagundi

Labua kalembanguni

Kalembangu bhakeno

Labuansum-suru

mbungano

Mbunga sembunga-

mbungano

\section{Prinsip Sikap Baik}

Setelah membaca dan mencermati kandungan isi dari Kabanti Ngkitaana di atas, maka peneliti dapat mengemukakan nilai moral berupa prinsip Sikab Baik dalam bentuk nasihat kepada semua manusia. Walaupun nasihat-nasihat itu dalam bentuk tersirat, akan tetapi dapat dimakani betapa pentingnya kesadaran kita manusia tentang eksistensi kemanuasiaan.

Karena nasihat ini tersirat, maka tentu untuk memahaminya kita harus membancanya secara keseluruhan, dari awal sampai akhir teks lagu tersebut. Memang lagu ini tergolong sastra lama yang lebih bersifat filosofis. Lariklariknya mengandung makna yang luas, sehingga membutuhkan pemaknaan yang dalam bagi pembacanya.

\section{Prinsip Kerukunan}

Setelah membaca secara teliti teks Kabanti Ngkitaana, secara umum judulnya tentang mengemu-kakan tentang hakikat kita sebagai manusia. Setelah kita membaca larik-lariknya, barulah kita menangkap makna tentang manusia yang asalnya satu. Ibaratnya, kita manusia di dunia ini berasal dari satu pohon. Setelah itu menyebar ke seluruh penjuru dunia ibarat cabang-cabangnya.

Dari perumpmaan tersebut lalu kita dapat memhami bahwa syair Kabanti tersebut mengandung nilai moral berupa seruan kerukunan kepada seluruh umat manusia karena kita berasal dari satu. Karena kita berasal dari satu keturunan, maka marilah kita selalu bersatu, harus rukun antara satu keluarga dengan keluarga yang lain, antara bangsa yang satu dengan bangsa yang lain, dan seterusnya untuk kebaikan kita semua.

Seperti halnya dengan nilai moral yang lainnya, maka nilai moral yang bertelian dengan kerukunan ini dapat kita selami melalui pembacaan syairnya secara keseluruhan, karena nilai kerukunan ini tersirat di dalamnya secara filosofis.

\section{B. Nilai Moral Kabanti Yoai}

Tabe lain tabea Permisi! Permisi ! Aomangka powandi Nae tompamo Adik duluan lewat (turun)

kamborara

Lampangulu notingkulu Notingkulu rato idhia Ane sampumo wangu Tobhiru nungguawe Anembuli ntugu

Yang sakit akan turun

Turun menemui dia Kalau turun minta izin

Potonglah dengan daun Kalau pulang tunggulah

Kita turun berdua

Dhotingkulu

dharodua

Dhotingkulu

Berpegang tangan

Kita turun bersama

tokombowa

Topombuli

toponggaamo

Kita pulang

berpisahlah

Tapi tinggal kata-

kata

Isabharano wamba

Wa inamo pangulumo

Sawali maka iyau

Dan sang ibu yang sakit

Dopotingalu-

Padahal saja aku

ngalumo 


\section{Prinsip Sikap Baik}

Setelah membaca dan mencermati kandungan isi dari Kabanti Kabanti Yoai di atas, maka peneliti dapat mengemukakan nilai moral berupa prinsip Sikap Baik berupa santun kepada sesama. Pada larik pertama syair Kabanti Kabanti Yoai, pada intinya adalah menyangkut sopan santun saeorang adik keda kakaknya. Nilai moral berupa budaya pamitan sangat kental dalam budaya masyarakay Buton pada umumnya.

Ketika seseorang akan pergi meninggalkan suatu pertemuan, maka kata permisi (tabe) merupakan hal yang wajib diucapkan. Kata tabe tidak hanya merujuk kepada makna permisi, akan tetapi lebih luas dari itu. Kata tabe bermakna penghormatan lahir batin kepada sesama. Jadi kata tabe merupakan penanda santun disaat melintas di depan seseorang atau banyak orang atau disaat meninggalkan suatu pertemuan sekaligus sebagai wujud penghargaan kepada sesama. Ada harapan masyarakat agar nilai-nilai moral budaya semacam ini dapat dipanuti secara regenerasi dalam pergaulan sosial kemasyarakatan keseharian kita.

Nilai moral berupa sikap baik dalam bentuk menghargai sesama sangat penting dalam masyarakat Buton, karena hal ini diungkapkan sejak masih dalam kandungan. Hal ini dibuktikan dengan kan-dungan syair Kabanti Yoai yang mengisahkan dialog di alam gaib yaitu di alam kandungan. Ini berarti, nilai moral budaya semacam ini sejak di dalam kandungan telah dipermak-lumkan. Kita yakini bersama bahwa penanaman nilai moral sejak dini akan lebih efektif dalam upaya pembentukan generasi yang dapat melanjutkan pembangunan di masa yang akan datang.

\section{Prinsip Kerukunan}

Nilai moral dalam bentuk prinsip kerukunan dapat kita temukan dalam kutipan syair Kabanti Kabanti Yoai di atas. Memang makna larik-lariknya sangat filosofis, sehingga perlu pemaknaan yang dalam. Misalnya saja, dialog yang terjadi di alam kandungan merupakan hal yang sangat sakral. Antara sang kakak (ari-ari) dengan bayi dalam kandungan telah menujukkan sikap rukun antara mereka. Ketika sang bayi duluan lahir (duluan keluar rahim), terlebih dahulu dia meminta izin dengan kata tabe. Dan saat itu, sang kakak merestui atau mengizinkan untuk duluan turun atau lahir.

Tidak hanya itu, dialog mereka sangatlah rukun yang ditandai dengan pesan sang kakak kepada sang adik. Sang kakak memberi tahu sang adik agar kalau sudah tiba di sana (di dunia) nanti tunggu saya. Sang kakak berharap agar kalau pung nanti mereka bisa bersama-sama lagi. Artinya, kalau meninggal kelak, sang kakak berharap mereka bersamasama lagi.

Kerukunan antara sang kakak dengan sang adik nampak dalam sikap saling menasihati dan saling memperhatikan satu sama lain. Harapan mereka berdua saling berpegang tangan disaat turun atau lahir, dan perjanjian mereka untuk kembali bersamaan merupakan dialog yang terkesan mengharukan kita. Hati kita begitu jujur mengharapkan sussana rukun seperti ini. Semoga saja nilia moral kerukunan semacam ini dapat kita wujudkan dalam kehidupan kira sehari-hari. Hanya dengan rukun kita dapat menikmati kehidupan kita.

\section{Prinsip Hormat}

Nilai moral dalam bentuk rasa hormat dan patuh kepada ibu tercinta dapat kita temukan dalam syair Kabanti Yoai di atas. Dialog antara sang kakak dengan sang adik tentang bagaimana 
penderitaan sang Ibu ketika kita dilahirkan. Sang kakak mengingatkan kepada sang adik bahwa betapa sakitnya ibu disaat kita dalam kandungan. Kita berdua hanya bernapas pun, sang ibu sudah merasa kesakita. Apa lagi disaat kita sedang menunggu serta sedang dilahirkan.

Kesadaran akan nilai moral tentang rasa hormat kepada ibu sangat penting bagi setiap manusia sebagai wujud dari rasa hormat kita kepada jasa ibu saat mengandung dan meliharkan kita. Hormat dan patuh kepada ibu merupakan nilai moral yang sangat penting dalam kehidupan setiap insan. Bahkan, sikap hormat dan patuh kepada ibu merupakan penanda sosok anak yang sukses. Sangat kita yakini bahwa hanya orang yang hormat dan patuh kepada ibunya yang dapat meraih kehidupan yang berkah. Sebaliknya, bagi siapa saja yang tidak menghargai atau tidak menghormati ibunya, maka ia tergolong orang yang durhaka.

\section{Nilai Moral Kabanti Yoisa}

$\begin{array}{ll}\text { Wa aka maimo } & \text { Sang kakak marilah } \\ \text { sampu } & \text { turun } \\ \text { Wa andi } & \text { Sang adik sudah } \\ \text { nopangulumo } & \text { gelisah (sakit) } \\ \text { Maimo dhia maimo } & \text { Marilah! marilah! } \\ \text { Koe dhia mbalengo } & \text { Jangan tetap } \\ & \text { enggan (bersama) } \\ \text { Ambea lengomo } & \text { Kalau tetap enggan } \\ \text { bhela } & \text { Kesedihan telah } \\ \text { Ngkapea } & \text { menunggumu } \\ \text { neantagimo } & \text { Aku sudah memang } \\ \text { lyau ngahanea } & \text { begini } \\ \text { nomo } & \text { Nanti ku susuli } \\ \text { Madhapo amangka } & \\ \text { tulu } & \\ \text { Atumutumo kabhori } & \text { Kututupi ketetapan } \\ \text { Kabhori minae } & \text { (tulisan) } \\ \text { yopu } & \text { Ketetapan dari } \\ \text { Kasukara } & \text { Tuhan } \\ \text { lancangia } & \text { Kesukaran } \\ \text { Kokombe ntagia } & \text { sebelumnya (tanda } \\ \text { Bharanomo } & \text { Tanda sebelumnya) } \\ \text { mpulawangi } & \text { Kuterjatuh } \\ \text { bertahan }\end{array}$

$\begin{array}{ll}\begin{array}{l}\text { Atuamangi koesu } \\ \text { lyau amokulamo }\end{array} & \begin{array}{l}\text { Untunglah } \\ \text { melawannya } \\ \text { Kacintampe }\end{array} \\ \text { Kampangulu } & \begin{array}{l}\text { Kutan dirimu } \\ \text { (kamu) } \\ \text { Daun untuk yang } \\ \text { gelisah } \\ \text { (sakit) }\end{array} \\ \text { Dhamule-muleimo } & \text { (telah) hilang } \\ \text { Kasimbi garanano } & \text { sedikit demi } \\ \text { uwe } & \text { Sedikit (tak ada } \\ \text { Dhamotembe- } & \text { panasnya) } \\ \text { tembemo } & \text { Aku bersusah-susah } \\ \text { Amoa-moaleimo } & \text { Gelisah dan gelisah } \\ \text { Asambi waambie } & \text { (kalau) } \\ \text { Ambo } & \text { kawasakalambe } \\ \text { kawasakalambe } & \text { Kasihan aku ini } \\ \text { Kaasi yau wana } & \end{array}$

\section{Prinsip Kerukunan}

Nilai moral dalam bentuk prinsip kerukunan dapat kita temukan dalam kutipan syair Kabanti Yoisa di atas. Memang makna larik-lariknya sangat filosofis, sehingga perlu pemaknaan yang dalam. Kita agak kesulitan jika handak mengartikannya kata demi kata bahkan perlarik. Akan tetapi jika kita maknai secara keseluruhan barulah nampak berbagai nilai yang terkandung di dalamnya.

Dialog antara kaka dengan adik di alam gaib merupakan panutan bagi kita dalam membentuk kehidupan keluarga atau sosial kemasyarakatan. Antara adik dengan kakak begitu rukun dalam proses kelahirannya. ajakan sang adik kepada kakak agar kita secepatnya keluar (lahir) karena adik sudak kesakitan terkesan mengharukan.

Sang adik bermohon kepada kaka agar secepatnya kita keluar jangan sampai ada sesuatu yang menyedihkan. Dalam hal ini, jika terlambat keluar (lahir) jangan sampai ada resiko yang tidak diinginkan. Dengan demikian kegelisahan adik nampak dicurakan keda sang kakak. Nilai moral kerukunan di antara adik dengan kakak nampak dalam komunikasi yang sangat toleran dan saling mengiundahkan di antara mereka adik dan kakak. 
Kita yakin bersama bahwa jika penanaman nilai-nilai moral kerukunan ditanamkan sejak dini bagi generasim kita, tentu akan lebih memudahkan kita dalam mempersiapkan generasi yang dihandalkan pada masa yang aka datang. Generasi yang tangguh, adalah generasi yang tidak hanya memiliki kecakapan intelegensi, akan tetapi juga harus memiliki kecakapan emosional serta kecakapan spritual. Ketiga kompetesni inilah yang menjadi kunci dalam mewujudkan masyarakat yang madani, yaitu masyarakat yang dapat membangun kondisi bangsa yang lebih damai dan makmur. Hanyalah dengan situasi yang rukun diantara warga yang dapat menciptakan kedamaian, kesejahteraan yang demokratis.

\section{Prinsip Hormat}

Dialog yang sangat harmonis di antara kakak dengan adiknya merupakan wujud dari nilai saling menghirmati di antara mereka berdua. Saling menghormati antara kakak dan adik dapat terwujud jika sang adik menghargai dan menghirmati kakaknya. Demikian pulan, sang kakak harus menyayangi adiknya.

Hubungan harmonis semacam itu tidaklah mudah diciptakan. Orang tua sangat dibutuhkan peranannya dalam pembinaan ke arah ini. Sejak dini orang tua sudah harus menegaskan dalam berbagai wujud pembinaan kepada anakanak mereka. Jika teralanjur dewasa, biasanya sang anak sudah agak rumit untuk dibentuk watak dan jiwanya.

Secara umum, peneliti dapat mengatakan bahwa nilai moral dengan prinsip hormat-menghormati semacam ini penting untuk diwujudkan dalam kehidupan kelurag, masyarakat bangsa dan negara. Penerapan nilai moran dalam bentuk saling menghirmati semacam ini merupakan kunci sukses upaya penguatan ketahanan nasional. Hanya bangsa yang saling menghirmati yang dapat menciptakan kenyamanan dan kesejahteraan yang demokratis.

\section{Prinsip Ketuhanan}

Nilai moral dalam bentuk prinsip Ketuhanan dapat kita temukan dalam kutipan syair Kabanti Yoisa di atas. Kita perlu memaknai secara mendalam, karena untaian kata-kata serta lariknya sangat filosofis, sehingga perlu pembacaan dan pemaknaan secara mendalam. Kita agak kesulitan jika handak mengartikannya kata demi kata bahkan perlarik. Akan tetapi jika kita maknai secara keseluruhan barulah nampak berbagai nilai yang terkandung di dalamnya.

Kehadiran kata Tuhan dalam bait ketiga syair Kabanti Yoisa di atas, hanya dapat kita maknai jika menghunungkannya dengan lari-larik sebelumnya. Bahkan akan lebih akurat kita maknai eksistensi kata Tuhan dalam syair tersebut jika kita melakukan pemaknaan secara keseluruhan, dari larik pertama hingga larik terakhir.

Setelah kita membaca keseluruhan syair tersebut, barulah kita menemukan makna kata ketetapan Tuhan dalam konteks yang sebenarnya. Ketetapan Tuhan yang dimaksud dalam teks itu adalah ketetapan Tuhan dalam hubungannya dengan kelahiran sang bayi. Bahkan secara lebih luas, ketetapan Tuhan sesungguhnya juga termasuk keselamatan, nasip dan sebagainya yang segalannya telah ditentukan oleh Tuhan sebelum bayi itu lahir ke dunia.

Keyakinan atas ketetapan Tuham merupakan nilai moral yang berdasarkan prinsip Ketuhanan yang terkandung dalam syair Kabanti Yoisa dan juga dianut oleh masyarakay Waborobo. Wawaupun penelitian ini objeknya di kelurahan Waborobo, akan tetapi konsep atau prinsip Ketuhanan semacam ini harus berlaku dan diberlakukan dalam semua masyarakat muslim dimana saja berada. 


\section{PENUTUP}

Keseluruhan pembahasan yang telah dijelaskan pada pembahasan. Disimpulkan bahwa syair Kabanti Ganda yang berjudul Kabanti Ngkitaana, Kabanti Yoai dan Kabanti Yoisa, mengandung nilai-nilai moral sebagal berikut

1. Nilai Moral dalam Kabanti Ngkitaana, meliputi:

a. Prinsip sikap baik, berupa; pentingnya kesadaran kita manusia tentang eksistensi kemanuasiaan.

b. Prinsip kerukunan berupa seruan kerukunan kepada seluruh umat manusia karena kita berasal dari satu.

2. Nilai Moral dalam Kabanti Yoai, meliputi:

a. Prinsip Sikap Baik dalam bentuk kata tabe merupakan penanda santun disaat melintas di depan seseorang atau banyak orang atau disaat meninggalkan suatu pertemuan sekaligus sebagai wujud penghargaan kepada sesama.

b. Prinsip Kerukunan dalam bentuk sikap saling menasihati dan saling memperhatikan satu sama lain atau sikap saling menasihati dan saling memperhatikan satu sama lain.

c. Prinsip Hormat dalam bentuk rasa hormat dan patuh kepada ibu tercinta.

3. Nilai Moral dalam Kabanti Yoisa, meliputi:

a. Prinsip Kerukunan dalam bentuk komunikasi yang sangat toleran dan saling mengindahkan di antara mereka adik dan kakak.

b. Prinsip Hormat dalam wujud sang adik menghargai dan menghirmati kakaknya. Demikian pulan, sang kakak harus menyayangi adiknya.

c. Prinsip Ketuhanan dalam wujud keyakinan atas ketetapan Tuhan.

\section{DAFTAR PUSTAKA}

Apitukey, Leo. 2010. Struktur Sastra Lisan Totemboan. Jakarta: Depdikbud
Baker, S.J.W.J. 2011. Filsafat Kebudayaan sebuah Pengantar. Yogyakarta: Kanisius

Danandjaja, James. 2011. Folklor Indonesia (Ilmu Gosip, Dongeng, Dan Lainlain). Jakarta: Gratin

Darmadi, Hamid. 2010. Dasar Konsep Pendidikan Moral. Bandung: Alfabet.

Depdikbud. 2009. Sastra Lisan Dairi. Jakarta: Pusat Pembinaan dan Pengembangan Bahasa

Ema, Husna. 2010. Apresiasi sastra Indonesia. Bandung: Angkasa

Gafar, Zainal Abidin. 2011. Struktur Sastra Lisan Musi. Jakarta: Depdikbud

Harimanto dan Winarno. Mustopo, 2012. Ilmu Sosial Budaya Dasar. Jakarta Timur: Bumi Aksara.

Kridalaksana, Harimukti. 2012. Kamus Linguistik II. Bandung: Angkasa

Mustopo, M. Habib. 2012. Ilmu Budaya Dasar, Kumpulan Esai dan Budaya. Surabaya: Usaha Nasional

Ratna, Nyoman Kutha. 2015. Teori Metode dan Teknik Penelitian Sastra. Yogyakarta: Pustaka Pelajar

Salam, B. 2013. Etika Individual (Pola Dasar Filsafat Moral). Jakarta: Rineka Cipta.

Sarjono, Partin. 2013. Pengantar Pengkajian Sastra. Bandung: Pustaka Wina

Setia, Edy. 2014. Fungsi dan Kedudukan Sastra Melayu Serdang. Jakarta: Balai Pustaka

Simanjuntak, B. Simorangkir. 2015. Kesusastraan Indonesia I dan II. Jakarta: Pembangunan

Suprihadi, Sastro Supono. 2010. Menghampiri Kebudayaan. Bandung: Pustaka Wina

Soemardjan, Selo dan Soelaeman Soenardi. 2012. Setangkai Bunga Sosiologi. Jakarta: Yayasan Badan Penerbit Fakultas Ekonomi Universitas Indonesia.

Suseno, F. M. 2011. Etika Dasar: Masalahmasalah Pokok Filsafat Moral.Yogyakarta: Kanisius. 
Totobuang, Vol. 6, No. 2, Desember 2018: 283-296

Suseno, F. M. 2010. Etika Jawa: Sebuah Analisa Falsafi tentang KebijaksanaanHidup Jawa. Jakarta: PT. Gramedia Pustaka Utama.

Teeuw, A. 2010. Khasanah Kesusastraan Indonesia. Jakarta: Balai Pustaka

Tylor, E.B. 2014. Primitive Culture. (Terjemahan Oleh Anonim). New York; Brentano's.
Wahid, Sugira. 2015. Kapita Selekta, Kapita Sastra. Makassar: Berkah Utami

Zainal, Abdul Razak, dkk. 2016. Kamus Istilah Sastra. Jakarta: Balai Pustaka

Zubair, A. C. 2016. Kuliah Etika. Jakarta: Rajawali Press.

Zulvita, Eva, dkk. 2013. Wujud Arti dan Fungsi Puncak-Puncak kebudayaan Asli dan Lama Bagi Masyarakat Pendukungnya. Jambi: Depdikbud 